ARTICLE HISTORY: Received: March 10, 2021 Accepted: May 15, 2021 Published: May 19, 2021

ОДНО ИЗ ОСНОВНЫХ НАПРАВЛЕНИЙ И МАСШТАБОВ МИГРАЦИИ ЗА РУБЕЖОМ

\author{
Кырыкбаева Эльмира Омарбековна \\ Кандидат исторических наук, \\ доцент кафедры общеуниверситетских гуманитарных дицсиплин \\ Египетского университета исламской культуры «Нур-Мубарак»
}

\title{
ONE OF THE MAIN DIRECTIONS AND SCALES OF MIGRATION ABROAD
}

\author{
Kyrykbaeva Elmira Omarbekovna \\ Candidate of Historical Sciences, \\ Associate Professor of the Department of General University Humanities of \\ the Egyptian University of Islamic Culture "Nur-Mubarak»
}

\begin{abstract}
Аннотация. В статье были рассмотрены некоторые направления миграции. В современном мире процессы миграции призваны содействовать экономическому развитию и взаимообмену (как в Казахстане, так и за его пределами) прогрессивными технологиями и знаниями, взаимопроникновению культур. В то же время были анализированы некоторые моменты процесса внешней миграции, которые могли сопровождаться такими негативными последствиями, как усиление оттока за рубеж высококвалифицированных кадров и специалистов, потеря финансовых средств от казахстанских граждан, эмигрирующих или работающих за границей, развитие криминальных структур, специализирующихся на незаконной поставке рабочей силы в ближнее и дальнее зарубежье, рост масштабов нелегальной миграции и др.

Abstract. The article discusses some areas of migration. In the modern world, migration processes are designed to promote economic development and the exchange (both in Kazakhstan and abroad) of advanced technologies and knowledge, the interpenetration of cultures. At the same time, some aspects of the process of external migration were analyzed, which could be accompanied by such negative consequences as increased outflow of highly qualified personnel and specialists abroad, loss of financial resources from Kazakhstani citizens emigrating or working abroad, the development of criminal structures specializing in the illegal supply of labor to near and far abroad, the growth of illegal migration, etc.
\end{abstract}

Ключевые слова: миграция, иммиграция,депортация, миграционная политика,легально, рабочая сила.

Keywords: migration, immigration, deportation, migration policy, legally, labor force.

Международная миграция возникает при наличии значительных контрастов в уровнях и условиях экономического развития и темпах естественного прироста населения стран, принимающих или отдающих рабочую силу. Поэтому географическими центрами иммиграции являются наиболее экономически развитые страны, такие, как США, Канада, Австралия, большинство западноевропейских стран, а также страны, где в связи с бурным экономическим ростом в результате высоких доходов от продажи нефти, наблюдается массовая иммиграция рабочей силы. К ним можно отнести Кувейт, Катар, Саудовскую Аравию, ОАЭ, Бахрейн.

В то время как большинство стран мира продвигаются по пути либерализации своей внешней торговли, одновременно практически все они принимают меры, ограничивающие международную миграцию рабочей силы.

Один из негативных эффектов миграции - это финансовое бремя, которое мигранты возлагают на бюджет более развитых стран. Особенно это четко проявляется, когда развитые страны близко расположены или даже граничат с менее развитыми странами. Типичным примером являются, с одной стороны, США, Мексика и страны Карибского бассейна, с другой стороны - Франция и страны Магриба, Германия и Турция. Такое близкое соседство приводит к наплыву не только легальных, но и нелегальных иммигрантов, которые требуют финансовых расходов либо для материальной поддержки, либо для депортации.

Поскольку страны-импортеры испытывают огромный приток рабочей силы, то, соответственно, их миграционная политика отражает национальные интересы данного государства. И основная ее задача - это селекция и отбор претендентов.

При выборе концепции миграционной политики большое значение имеют национально-исторические особенности страны [1, С.51].

Так, правительства стран Европейского сообщества, ставя своей целью создание единого международного рынка труда, исходят из концепции интеграции. Напротив, для политики США, Канады, Австралии более типичной является концепция ассимиляции или натурализации, так как массовый приезд иностранной рабочей силы в этих государствах в основном совпал с процессом формирования нации. Очевидно, что данная 
концепция не соответствовала условиям Западной Европы с ее исторически сложившимися нациями и высокой плотностью населения.

Несмотря на очевидные «выгоды» для предпринимателей принимающих стран, в современных условиях концепция ротации уже не может претендовать на официальное признание правительствами стран ЕС, так как ее недемократические и административные принципы находятся в противоречии с декларируемыми идеями интеграции Западной Европы.

На смену концепции ротации пришла идея интеграции. Как показал социологический опрос, проведенный в Германии среди большинства обследованных групп рабочих-мигрантов, доля лиц, не планирующих возвращение на родину, достаточно высока и колеблется в пределах 6,7\%-40,1\% [2, С.56].

Таким образом, каждый четвертый мигрант в Германии предполагает остаться в стране пребывания. При этом доля мигрантов, не планирующих возвращение на родину, продолжает возрастать не только в Германии, но и в ряде других стран ЕС.

В основе практических решений Совета ЕС по вопросам трудовой миграции лежит идея о том, что масштабы иммиграции должны определяться не только численностью рабочей силы на рынке, которая нуждается в работе, но и реальными потребностями национальной экономики в рабочей силе.

В настоящее время в рамках общего рынка рабочей силы стран ЕС миграционная политика формируется под влиянием двух определяющих факторов:

- рассматриваемая в недавнем прошлом как «временное явление», рабочая сила обрела статус одного из важных компонентов, оказывающих влияние на экономику, независимо от хозяйственной конъюнктуры в странах-импортерах;

- происходит постепенное увеличение средней продолжительности пребывания мигрантов в странереципиенте. Трудящийся-мигрант становится во все большей мере долговременным жителем стран-импортеров, что меняет сам характер межгосударственной трудовой миграции.

Учитывая, что одной из важнейших целей иммиграционной политики является защита национального рынка труда от неконтролируемого притока рабочей силы, государства-импортеры рабочей силы применяют меры, направленные на предотвращение иммиграции и сокращение числа иностранной рабочей силы.

К числу этих мер относится пресечение несанкционированного законодательством въезда в страну рабочих-мигрантов. Нелегальная миграция получила широкое распространение практически во всех странахимпортерах рабочей силы. Например, в США, по различным оценкам, проживает от 6 до 12 млн. незарегистрированных мигрантов.

Для борьбы с нелегальными мигрантами широко применяются методы депортации и интернирование незаконно проникших в страну иностранцев.

Одновременно с ужесточением политики по отношению к нелегальным иммигрантам законодательство США предусматривало право на легализацию части иностранцев, находившихся в США. Учитывая интересы крупного агробизнеса, было сделано исключение для сезонных сельскохозяйственных рабочих.

В настоящее время легализации незарегистрированных мигрантов в США препятствует длинный ряд бюрократических препон: получение разрешения на конкретную трудовую деятельность, задержки с установлением квот, свидетельство о знании английского языка и американского законодательства и т.д.

Иммиграционное законодательство содержит меры воздействия по отношению к нанимателям, использующим труд нелегальных иммигрантов в виде штрафных и судебных санкций. Подобная практика наблюдается в Нидерландах, Германии, Люксембурге, Бельгии и др.

Особенно строгие меры принимаются к посредникам, занимающимся поставкой нелегальной миграции. Так, во Франции за такие преступления законодательством предусмотрено наказание лишением свободы на срок от 2 до 5 лет или взыскание штрафа от 10 до 200 тысяч французских франков.

Большинство стран-импортеров рабочей силы приняли государственные программы стимулирования репатриации официально зарегистрированных рабочих, то есть реэмиграции. В отличие от административных методов здесь преобладают экономические стимулы. Принятые программы носят селективный характер, так как рассчитаны на поощрение репатриации только определенной категории мигрантов: лиц, нежелательных для страны-импортера, представителей, не пользующихся спросом на национальных рынках труда профессий.

В США для получения визы на въезд необходимо получить так называемый трудовой сертификат официальное подтверждение от фирмы или компании о согласии предоставить рабочее место, заверенное Министерством труда США, причем процесс получения этого документа является весьма сложной и длительной процедурой. Максимальный срок, на который выдается виза иммигранту, не может превышать 2-х лет, а продление и возобновление этой визы является крайне трудоемким процессом, требующим практически заново выполнять все иммиграционные требования.

Иммиграционное законодательство США устанавливает, что прежде чем выдать трудовой сертификат, Министерство труда США должно убедиться в том, что на месте предполагаемого трудоустройства иностранца в данное время нет американских рабочих, которые имеют достаточную квалификацию для выполнения определенной работы, для которой подходит и на которые претендует иностранец. Кроме того, должно быть 
установлено, что трудоустройство иностранца не окажет отрицательного влияния на заработную плату или условия труда американских рабочих. Трудящийся-мигрант не вправе по собственному усмотрению сменить место работы, район проживания или прочие условия контракта, рискуя быть депортированным из США.

Большинство принимающих стран используют селективный подход при регулировании иммиграции. Его смысл заключается в том, что государство не препятствует въезду тех категорий работников, которые нужны данной стране, ограничивая въезд всем остальным. Перечень желательных иммигрантов варьируется от страны к стране, но обычно они относятся к одной из следующих категорий:

- работники, готовые за минимальную оплату выполнять тяжелую, вредную, грязную, неквалифицированную работу - строители, подсобные, сезонные, вахтенные, муниципальные рабочие;

- специалисты для новых и перспективных отраслей экономики -программисты, узкоспециализированные инженеры, банковские служащие;

- представители редких профессий, например, огранщики алмазов, реставраторы картин, врачи и т.д.;

- специалисты с мировым именем - музыканты, артисты, ученые, спортсмены, врачи, писатели и т.д.;

- крупные бизнесмены, инвестирующие капитал в принимающую страну и создающие новые рабочие места. [3, С.29].

Качество рабочей силы определяется наличием образования или квалификации, признаваемых в странеимпортере. Существует необходимая процедура признания имеющихся у мигранта документов об образовании или профессиональной подготовке.

По этому вопросу в Европейском Союзе было принято решение, согласно которому начиная с 1991 года на всей территории ЕС, равно признаются все дипломы о высшем образовании, полученные в одной из странчленов. Дипломы, полученные в третьих странах (не входящих в ЕС), могут быть признаны при условии, что их обладатели как минимум 3 года отработали по данным дипломам в одной из стран ЕС.

Для решения об окончательной сопоставимости дипломов был выработан ряд критериев, одним из которых является требование получить высшее образование любого типа в течение 3 лет.

Требование опыта работы по специальности является еще одним из свидетельств высоких запросов принимающей страны к качеству иностранной рабочей силы. Наиболее высоко оцениваются шансы на получение въездной визы у тех мигрантов, которые имеют «значительный и положительный опыт работы по дефицитной специальности», что означает стаж работы не менее 3 лет перед подачей заявления на иммиграцию.

Регулирование численности прибывающих мигрантов осуществляется с помощью ежегодно рассчитываемой в странах-импортерах иммиграционной квоты. Расчет иммиграционной квоты производится достаточно сложным путем. Здесь во внимание принимаются экономические потребности государства, оценка демографической ситуации с учетом прогноза численности населения, учитывается также состояние национальных рынков труда и жилья. Большое значение на размеры квоты оказывает политическая конъюнктура в стране-импортере. Например, в Канаде общая квота, выделяемая правительством в 1994 году, составила 270 тыс. чел. [4, С.173].

Выделяемая правительством страны-импортера иммиграционная квота может быть распределена в определенной пропорции между различными категориями мигрантов с учетом их приоритетности для страны. В США в 1995 г. распределение квоты составило: 7\% - родственники граждан США, 20\% - специалисты, в которых нуждается США, 9\% - прочие группы иммигрантов и т.д.

К числу прочих требований, предъявляемых к качеству рабочей силы, можно отнести:

- требование хорошего состояния здоровья у прибывающих мигрантов;

- дополнительные профессиональные требования, относящиеся к ряду специальностей или профессий. В США, например, иностранный программист должен владеть принятыми в стране программными средствами, быть знаком с компьютерными системами;

- ограничения личностного и психологического плана. Так, например, претендент на получение гражданства ЮАР должен иметь «добрый характер». В США издавна ограничен въезд для представителей любой из партий тоталитарного типа.

Для отбора кандидатов применяются различные методики. Так, в Канаде и Австралии используется система оценок каждого кандидата в баллах. В Канаде кандидаты на иммиграцию оцениваются по 10 критериям, за каждый из которых они могут получить от 8 до 15 баллов при проходной сумме баллов равной 70 [4, С.174].

Согласно американскому иммиграционному законодательству, иностранец имеет право получить визу и поселиться в США, если он намерен вложить как минимум 500 тыс. долларов в американские предприятия с целью их расширения. Затем дается испытательный срок в 2 года, с тем чтобы претендент мог продемонстрировать свои деловые качества.

Несмотря на то, что правительство каждой страны суверенно в своем праве определять направления и цели миграционной политики при разработке комплекса мер, регулирующих процессы внешней трудовой миграции, существуют определенные правовые стандарты, закрепленные в документах международных организаций. 


\section{СПИСОК ИСПОЛЬЗОВАННОЙ ЛИТЕРАТУРЫ:}

1.Дадаев О.К. Актуальные проблемы внешней трудовой миграции граждан России. Дисс. на соиск.науч.степени д.э.н. М., 1997, 296 с.

2. Васильев Г.В. Эмигранты. М., 1990. С. 2-41.

3. Ионцев В.А. Мировые миграции. М., 1992, 68 с.

4.Каменский А.Н. Миграция рабочей силы как форма внешнеэкономических связей стран Ближнего Востока. Дис. на соиск. уч. степени к.э.н. М, 1982, С.40.

\section{REFERENCES:}

1. Dadaev O.K. Actual problems of external labor migration of Russian citizens. Diss. for the degree of Doctor of Economics M., 1997, 296 p.

2. Vasiliev G.V. Emigranty. M., 1990. P. 2-41.

3. Iontsev V.A. Mirovyye migratsii. M., 1992, 68 p.

4. Kamensky A.N. Labor migration as a form of foreign economic relations of the countries of the Middle East. Dis. for a job. uch. Ph.D. degree M, 1982, P.40. 